- hacer una reflexión crítica que contraste los aspectos teóricos planteados en la investigación con la información relevada durante el trabajo de campo, para posibilitar el comienzo de la reconstrucción de una teoría pedagógica que permita desarrollos ulteriores del quehacer pedagógico acordes con nuestra realidad colombiana.

\title{
LA IMAGEN DEL MAESTRO RURAL
}

Los estudios sobre educación rural realizados por las diversas entidades y/o personas que se interesan por este tema en el medio colombiano, han abarcado hasta el momento aspectos imprescindibles para el conocimiento y el diagnóstico de los principales logros y problemas del servicio educativo ofrecido en las áreas rurales. Tal es el caso, por ejemplo, de los trabajos existentes sobre la cobertura del sistema y la evaluación del rendimiento escolar, las fuentes de financiación y la administración del presupuesto educativo, la formación y capacitación del personal docente, la legislación e historia de la educación rural, las técnicas y concepciones pedagógicas implementadas en el área, los inventarios de recursos didácticos y de infraestructura.

Aunque semejante diversidad de tópicos indican la existencia de un conocimiento bastante amplio sobre el estado actual de la educación rural, también es posible señalar que entre todos ellos, la dimensión social de la educación es quizá la más olvidada, por cuanto, en la mayoría de los casos, no se ha visto su utilidad práctica inmediata en términos de formulación de políticas o de asignación de recursos presupuéstales.

En efecto, son excepcionales los casos en los cuales los intereses de los investigadores en educación se han orientado hacia el análisis de aquellas situaciones y factores que en un momento dado permitirían una adecuada interpretación del significado dado a la educación, la escuela y el maestro en las comunidades a las cuales pretenden servir; y, por tanto, del tipo de relaciones e interacciones que es posible encontrar, y de las que sería deseable llegar a establecer entre todos los actores del proceso educativo en comunidades rurales. El interés de este proyecto es abrir una nueva línea de investigación en esta dirección a partir de un estudio que, por sus objetivos y dimensiones, sólo pretende explorar el tema.

El objetivo central del estudio es pues llegar a conocer, para el caso de dos escuelas rurales incompletas -que podrían considerarse típicas de las regiones campesinas colombianas - cuál es la imagen del maestro rural ante sí mismo, ante sus alumnos y ante la comunidad en la cual trabaja.

Por otra parte, como la categoría analítica Imagen del Maestro conlleva distintas dimensiones, también es propósito del estudio explorarlas sobre el terreno y re-definirlas si es necesario, establecer las posibles incongruencias y contradicciones existentes entre ellas e identificar las causas probables de las mismas.

Además, se ha procurado seleccionar las escuelas de manera tal que las dos pertenezcan a comunidades rurales con características sociales, económicas y culturales similares, con el propósito de neutralizar, hasta donde sea posible hacerlo, la influencia de factores ajenos a las condiciones específicas del docente en las diferencias que, como se prevé, podrán hallarse en las interacciones maestro-alumnos, maestro-comunidad. 
Dentro de esta perspectiva, la relación maestro-alumno y la dinámica que necesariamente ella genera, componentes de la dimensión pedagógica de la imagen del maestro, será cuidadosamente analizada.

Para el desarrollo del trabajo de campo se emplearán técnicas antropológicas y sociológicas tales como: observación, observación participante, entrevista estructurada, semi-estructurada y abierta. Las fuentes primarias de información serán: el maestro, los alumnos, los padres de familia y otros miembros de la comunidad.

Rodrigo Parra 